\title{
A Large Chromosome in the Antheridium of Sargassum thunbergii (Mertens ex Roth) Kuntze (Phaeophyta)
}

\author{
Hiroshi $\mathrm{Yabu}^{1}$ and Norishige Yotsukura ${ }^{2}$ \\ ${ }^{1}$ Yunokawa-cho 2-11-11-705, Hakodate, Hokkaido, 042 Japan \\ ${ }^{2}$ Faculty of Fisheries, Hokkaido University, Minato-machi 3-1-1, \\ Hakodate, Hokkaido, 041 Japan
}

Accepted March 9. 1995

Dioecious Sargassum thunbergii (Mertens ex Roth) Kuntze (Fucales, Phaeophyta) widely distributing along the whole coast of Japanese territory (cf. Fig. 25, p, 147, Yosida 1983) is common and populous from spring through late autumn on the rocks in the tidal zone. Yabu and Tokida (1966) once reported that aceto-iron-haematoxyln-chloral hydrate method deviced and recommended by Wittmann (1965) showed excelent chromosome staining for various seaweeds including $S$. thunbergii. In their comunication, however none of the cytological accounts were given except submitting only a photomicrograph showing the dividing nuclei in green alga Chaetomorpha moniligela. Since then $S$. thunbergii has been left untouched for cytology, so in order to determine the chromosome number of $S$. tunbergii, we carried out this study.

\section{Material and methods}

The maturing antheridial receptacles used had been taken from the male plants during the months from June to October in the years 1990-1994, at Usujiri or Shinori near or in Hakodate, Hokkaido. They were treated with the procedure of the above-mentioned aceto-ironhaematoxylin-chloral hydrate method. The best periods to find the dividing nuclei in the antheridia were late September through mid-October.

\section{Results and discussion}

Within the antheridia, we could count 32 chromosomes (Fig. 1) from late prophase to early metaphase in the first nuclear division known as Meiosis I, and one of the chromosomes was recognized as a large element (Fig. 2). The dividing nuclei in the following successive five nuclear divisions leading to the 64 spermatia formation were incapable for the count of definite chromosome numbers due to the dense gathering of chromosomes in the decreased area of the nuclear cavity, but sometimes displayed to have ca. 30 chromosomes. The metaphase nuclei in such successive divisions were also found to provide one large element (Figs. 3-5).

In the genus Sargassum, more than 350 species are said to comprise (May and Clayton 1991), however the chromosome number has been recorded only for the following six species, all from the localities in Japan: $S$. confusum $(n=32$, Abe 1933; $4 \mathrm{n}=64$, Yabu and Yasui 1983), $S$. everve $(\mathrm{n}=32,2 \mathrm{n}=\mathrm{ca} .60$, Tahara and Shimotomai 1926), $S$. horneri $(\mathrm{n}=16,2 \mathrm{n}=32$, Kunieda 1928; $n=32$, Okabe 1929; $2 n=64$, Okabe 1930; $n=32$, Hiroe and Inoh 1954a), $S$. patens $(2 n=64$, Hiroe and Inoh 1954a), S. piluliferum $(n=32,2 n=64$, Inoh and Hiroe 1954a), $S$. tortile $(n=32$, Hiroe and Inoh 1956; $n=32$ Ogawa, Inoh and Ohmori 1969), and the chomosomes in these species were figured all as the spherical elements.

Those informations seem to suggest that the basic chromosome number for the Sargassum 


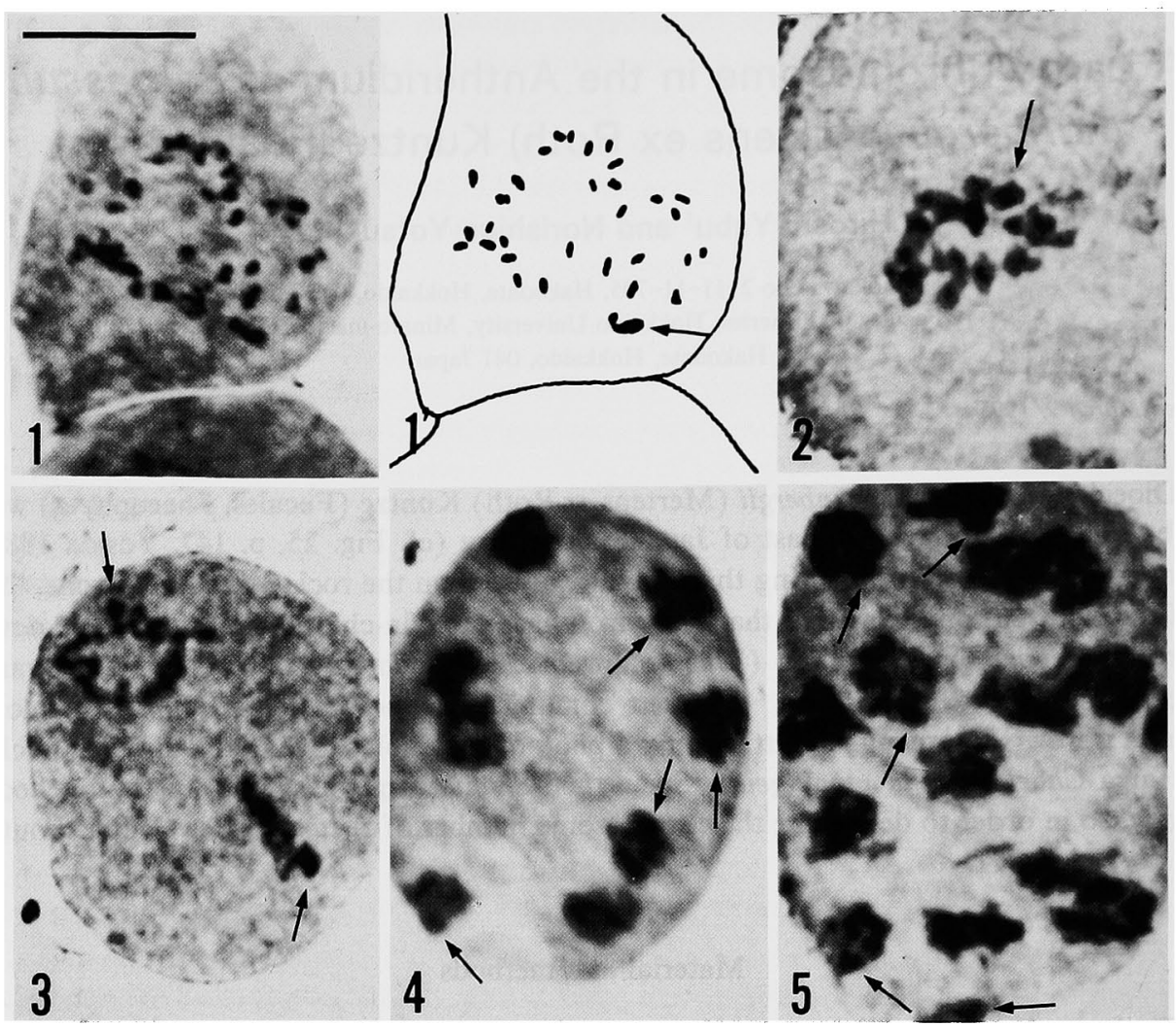

Figs. 1-5. Dividing nuclei in the antheridia of Sargassum thunbergii (Mertens ex Roth) Kuntze from Shinori in Hakodate, Hokkaido. 1, 2. Metaphase in the first nuclear division. 1'. Drawing of Fig. 1. 3. Metaphase in the second nuclear division. 4. Metaphase in the fourth nuclear division. 5. Metaphase in the fifth nuclear division. Large chromosome is indicated by arrows. Bar $=10 \mu \mathrm{m}$ for all figures.

species is $n=32$ and $2 n=64$. We confirmed in this study also $n=32$ chromosomes in the spherical shape for $S$. thunbergii. The presence of the same element as a large chromosome detected by us in $S$. thunbergii was already reported and figured as a somewhat larger gemini at meiosis in the oogonium of $S$. horneri by Okabe (1929). In our trials for $S$. thunbergii, we failed to examine the chromosome number and the presence of such a large chromosome in the dividing nuclei in the oogonium, to which we shall undertake the observations in the near future.

\section{Summary}

The chromosome number of Sargassum thunbergii (Mertens ex Roth) Kuntze (Fucales, Phaeophyta) was determined as $n=32$ at late prophase and early metaphase in the first nuclear divisions in the antheridia. One of the chromosomes was detected as a large element at metaphase in the nuclear divisions leading to the spermatia formation in the antheridia.

\section{References}

Abe, K. 1933. Mitosen im antheridium von Sargassum confusum Ag. Sci. Rep. Tohoku Imp. Univ., Biol. 8: $259-262$. 
Hiroe, M. and Inoh, S. 1954a. Cytological studies on the Fucaceous plants IV. On the mitotic division in the antheridium of Sargassum Horneri (Turn.) Ag. (Prelimnary note). Bot. Mag. Tokyo 67: 190-192 (In Japanese).

- and - 1954b. Cytological studies on the Fucaceous plants V. On the mitotic division in the embryo of Sargassum patens C. Ag. Biol. Jour. Okayama Univ. 2: 1-6.

- and - 1956. Cytological studies on the Fucaceous plants VI. On the meiotic division in the antheridium of Sargassum tortile C. Ag. (Preliminarry note). La Kuromosomo 27/28: 942-947 (In Japanese).

Inoh, S. and Hiroe, M. 1954. Cytological studies on the Fucaceous plants I. On the somatic mitosis in the embryo of Sargassum piluliferum C. Ag. (Preliminarry note). La Kuromosomo 21: 760-763 (In Japanese).

Kunieda, H. 1928. On the development of the sexual organs and embryogeny in Sargassum Horneri Ag. Jour. Coll. Agr. 9: 383-396.

May, D. I. and Clayton, M. N. 1991. Oogenesis, the formation of oogonial starks and fertilization in Sargassum vestitum (Fucales, Phaeophyta) from southern Australia. Phycologia 30: 243-256.

Ogawa, H., Inoh, S. and Ohmori, T. 1969. Meiosis in the oogonium of Sargassum tortile C. Ag. Bot. Mag. Tokyo 82; 45-52.

Okabe, S. 1929. Meiosis im oogonium von Sargassum Horneri (Turn.) Ag. Sci. Rep. Tohoku Imp. Univ., Biol. 4: 661669.

- 1930. Mitosen im Keimenden Embryo von Sargassum Horneri (Turn.) Ag. Ibid. 4: 551-556.

Tahara, M. and Shimotomai, N. 1926. Mitosen bei Sargassum. Ibid. 1: 189-192.

Wittmann, W. 1965. Aceto-iron-haematoxylin-chloral hydrate for chromosome staining. Stain Tech. 40: 161-164.

Yabu, H. and Tokida, J. 1966. Application of aceto-iron-haematoxylin-chloral hydrate method to chromosome staining in marine algae. Bot. Mag. Tokyo 79: 381.

— and Yasui, H. 1983. Occurrence of a tetraploid in Sargassum confusum Ag. Jap. J. Phycol. 31: 86-87.

Yoshida, T. 1983. Japanese species of Sargassum subgenus Bactrophycus. J. Fac. Sci., Hokkaido Univ. Ser. V (Botany) 13: 99-246. 